\title{
Public Health Nursing
}

National Cancer Institute

\section{Source}

National Cancer Institute. Public Health Nursing. NCI Thesaurus. Code C17040.

A discipline in nursing with a specific focus on health related concerns that can affect the general population; this includes high risk behaviors and communicable diseases. 